\title{
REVIEW
}

\section{Angiotensin receptor blockers in hypertension. New insights from Japan}

\begin{abstract}
Paolo Verdecchia ${ }^{1}$, Fabio Angeli ${ }^{1}$, Giovanni Mazzotta ${ }^{1}$, Giuseppe Ambrosio ${ }^{2}$ and Gianpaolo Reboldi ${ }^{3}$
Angiotensin II receptor blockers (ARBs) are widely used in the treatment of patients with hypertension, heart failure, diabetic nephropathy and other clinical conditions. Several intervention trials and systematic overviews showed that both angiotensinconverting enzyme inhibitors and ARBs effectively reduce the risk of stroke, myocardial infarction and congestive heart failure in hypertensive patients. Two recent intervention trials conducted in Japan (JIKEI and Kyoto studies) suggested that the protective effect of ARBs on major cardiovascular events might be partly independent from the degree of blood pressure (BP) reduction. Both studies used a prospective randomized open blinded end point (PROBE) design. No significant differences emerged in both studies between the ARB group (valsartan) and the control group in the achieved BP. We made a pooled analysis of the JIKEI and Kyoto studies. Overall, valsartan significantly reduced the risk of the primary composite outcome (by $42 \% ; P<0.0001$ ), angina pectoris (by $38 \% ; P<0.0001$ ), heart failure requiring hospitalization (by $43 \% ; P=0.013$ ) and cerebrovascular events (by $42 \% ; P=0.002$ ). The protective effect on the dissecting aneurysm of aorta bordered statistical significance. These data reinforce the notion that the protective effect of angiotensin II inhibition is partly independent of BP reduction. Hypertension Research (2010) 33, 394-397; doi:10.1038/hr.2010.13; published online 12 February 2010
\end{abstract}

Keywords: angiotensin-converting enzyme inhibitors; angiotensin receptor blockers; congestive heart failure; myocardial infarction; stroke

\section{INTRODUCTION}

Angiotensin II receptor blockers (ARBs) are increasingly used in the treatment of patients with hypertension, heart failure, diabetic nephropathy and other clinical conditions. The European Society of Hypertension/European Society of Cardiology (ESH/ESH) guidelines for the management of patients with hypertension include these drugs among first-line therapeutic options. ${ }^{1}$ Interestingly, the use of ARBs is not limited to subjects with cough or other contraindications to angiotensin-converting enzyme inhibitors (ACEIs). For example, in a large US sample of elderly patients with left ventricular systolic dysfunction, a recent hospitalization for heart failure and no contraindications to use of ACEIs, only $68 \%$ of subjects were actually taking ACEIs, whereas an additional $8 \%$ of subjects were receiving ARBs. ${ }^{2}$

A large number of intervention trials and systematic overviews provided convincing evidence that both ACEIs and ARBs are effective in reducing the risk of stroke, myocardial infarction (MI) and congestive heart failure, in hypertensive patients. ${ }^{3-5}$ Interestingly, some analyses suggested that at least part of the protective effect of these drugs on specific cardiovascular events such as MI and congestive heart failure might be independent of, or disproportionately greater than blood pressure (BP) reduction, ${ }^{6,7}$ hence suggesting that other mechanisms of cardiovascular prevention may also be operative in patients treated with these drugs.

\section{BP REDUCTION AND CARDIOVASCULAR PROTECTION OFFERED BY ARBS}

The argument that the protective effect of ARBs on major cardiovascular events is partly independent from the degree of BP reduction has been recently highlighted by two recent intervention studies conducted in Japan.

In the first of these studies, the Jikei study, ${ }^{8} 3081$ Japanese people with a mean age of 65 years who were being treated for hypertension, coronary heart disease or heart failure were assigned to either valsartan or other drugs not including angiotensin receptor blockers, in addition to the preexisting treatment. The median duration of follow-up was 3.1 years. At entry, BP was $139 / 81 \mathrm{~mm} \mathrm{Hg}$ in both groups. It fell to $131 / 77 \mathrm{~mm} \mathrm{Hg}$ in the valsartan group and $132 / 78 \mathrm{~mm} \mathrm{Hg}$ in the control group, without any statistical differences between the two groups. The primary end point, a composite of cardiovascular morbidity and mortality, occurred in 92 patients in the valsartan group and 149 patients in the control group (2.13 vs. 3.45 per 100 patient years; hazard ratio (HR) $0.61,95 \%$ confidence interval (CI) $0.47-0.79, P=0.0002)$. The advantage of valsartan over control was mainly attributable to a lower incidence of stroke and transient ischemic attack (HR 0.60, 95\% CI $0.38-0.95, P=0.028$ ), angina pectoris (HR $0.35,95 \%$ CI $0.20-0.58, P<0.0001$ ) and heart failure (HR 0.53; 95\% CI $0.31-0.94, P=0.029$ ) in the valsartan group.

${ }^{1}$ Struttura Complessa di Cardiologia, Unità di Ricerca Clinica 'Cardiologia Preventiva', Ospedale S Maria della Misericordia, Perugia, Italy; ${ }^{2}$ Università degli Studi di Perugia, Struttura Complessa di Fisiopatologia Cardiovascolare, Perugia, Italy and 3 Università degli Studi di Perugia, Dipartimento di Medicina Interna, Perugia, Italy Correspondence: Dr P Verdecchia, Struttura Complessa di Cardiologia, Unità di Ricerca Clinica 'Cardiologia Preventiva', Ospedale S Maria della Misericordia, Perugia. E-mail: verdec@tin.it

Received 29 October 2009; revised 11 December 2009; accepted 4 January 2010; published online 12 February 2010 
The second of these studies was the Kyoto Heart Study, ${ }^{9}$ an intervention study conducted in 3031 Japanese patients with a mean age of 66 years and uncontrolled hypertension. These patients were randomized to either valsartan add-on or non-ARB treatment. Median follow-up was 3.27 years. At entry, BP was $157 / 88 \mathrm{~mm} \mathrm{Hg}$ in both groups. It fell to $133 / 76 \mathrm{~mm} \mathrm{Hg}$ in both groups at the end of study. The primary end point, a composite of cardiovascular morbidity and mortality, occurred in fewer patients (HR 0.55, 95\% CI 0.42-0.72, $P<0.0001)$ in the valsartan group than in the control group. The outcome difference between the two groups was accounted for by lesser incidence of stroke and transient ischemic attack (TIA) (HR $0.55,95 \%$ CI $0.34-0.89, P=0.015$ ), and angina pectoris (HR $0.51,95 \%$ CI $0.31-0.86, P=0.011)$ in the valsartan group.

The Jikei study ${ }^{8}$ and the Kyoto Heart Study ${ }^{9}$ provide important new data that deserve to be discussed separately.

\section{EFFECTS OF ARBS ON THE RISK OF STROKE}

The higher frequency of stroke, relative to coronary artery disease, typical of the Japanese population ${ }^{10}$ could have facilitated the detection of a significant protective effect of valsartan over a traditional drug treatment devoid of ARBs. However, a preferential protective effect of ARBs on stroke emerged also in different studies conducted mostly in Caucasian individuals. For example, losartan induced a $25 \%$ reduction in the risk of stroke in the Losartan Intervention for End point Reduction (LIFE) Study, and such an effect accounted for most of the significant difference with respect to atenolol in the incidence of the primary outcome. ${ }^{11}$

We have recently completed a meta-analysis of available randomized head-to-head comparative trials conducted between ARBs and ACEIs. Six trials fulfilled the inclusion criteria, for a total of 49924 patients. ${ }^{12}$ In the pooled estimate, there were no significant differences between ARBs and ACEIs on the risk of MI (odds ratio (OR) 1.01, 95\% CI $0.95-1.07, P=0.75$ ), cardiovascular mortality (OR 1.03, 95\% CI $0.98-1.08, P=0.23$ ) and total mortality (OR 1.03 , 95\% CI $0.97-$ $1.10, P=0.20)$. However, the risk of stroke was slightly lower with ARBs than with ACEIs (OR 0.92, 95\% CI 0.85-0.99, $P=0.037$ ). ${ }^{12}$ These data support the hypothesis that ARBs may exert a specific, albeit modest, protective effect against stroke, which may further enhance the overall degree of cerebrovascular protection beyond the overwhelming benefit due to BP reduction. This may favor the use of ARBs in subjects at high risk of stroke, such as those with a previous history of stroke or TIA, or the Asian people. In this setting, it should be remarked that both the JIKEY and Kyoto studies were conducted against a non-ARB group, not an ACEI group. A large study that did not support an ARB benefit in stroke survivors was the Prevention Regimen for Effectively Avoiding Second Strokes (PRoFESS) Study. ${ }^{13}$ In this study, the rate of recurrent stroke did not differ between telmisartan and placebo. ${ }^{13}$ However, treatment was initiated quite early (within 90 days) after stroke and a trend toward a benefit in the ARB group seemed to emerged by the third year of follow-up. ${ }^{13}$

From a mechanistic point of view, experimental data suggest that ARBs might exert specific cerebrovascular protective effects, involving overstimulation of $\mathrm{AT}_{2}$ receptors by the overflow of angiotensin II, which is expected to occur after the administration of ARBs, but not with ACEIs that actually reduce $\mathrm{AT}_{2}$ receptor stimulation. In rats, the neurological outcome following induction of cerebral ischemia was improved by intracerebral administration of low doses of irbesartan, and such an effect was prevented by the coadministration of drugs blocking the $\mathrm{AT}_{2}$ receptors. ${ }^{14}$ In animal models of cerebral injury induced by cerebral artery occlusion, pretreatment with candesartan, but not with ramipril, effectively reduced the extent of infarct size. ${ }^{15}$
Direct support to the hypothesis of a protective effect of $\mathrm{AT}_{2}$ receptor stimulation is provided by a study in genetically modified animals, in which the neurological damage induced by cerebral ischemia was more severe in $\mathrm{AT}_{2}$ receptor-deleted mice than in control, wild-type mice. ${ }^{16}$

\section{EFFECTS ON ARBS ON THE RISK OF MI}

Some years ago, Verma and Strauss ${ }^{17}$ examined the results of randomized trials, which compared an ARB with a drug belonging to a different class in a variety of clinical conditions, including hypertension, heart failure and renal failure. These authors concluded that ARBs may increase the risk of MI, and that consequently patients had to be informed about the risk. ${ }^{17}$ These conclusions triggered a hot scientific debate and anxious reactions by many patients treated with ARBs. However, the statistical methodology of that study was seriously questioned, and several subsequent meta-analyses conducted using more rigorous techniques were unable to demonstrate any excess risk of MI in patients treated with ARBs, thereby contradicting such claim. ${ }^{18,19}$ In a meta-analysis from our group, cardiovascular mortality was significantly less with ARBs than with placebo (OR 0.91, 95\% CI $0.83-0.99, P=0.042) .{ }^{19}$ In a recent placebo-controlled study conducted in patients with high vascular risk, telmisartan reduced the risk of MI by $21 \%$, and such a reduction bordered statistical significance (HR $0.79,95 \%$ CI $0.62-1.01, P=0.07) .{ }^{20}$ Conversely, in a recent metaanalysis by Messerli et al., ${ }^{21}$ ARBs were associated with a not significant $8 \%$ higher risk of MI (HR 1.08, 95\% CI 1.00-1.18, $P=$ not significant). However, these authors did not report a sensitivity analysis of their study. This is an important limitation, because their pooled estimate was largely driven by one single study, the Valsartan Antihypertensive Long-Term Use Evaluation (VALUE) trial, ${ }^{22}$ in which the significant gradient between the two groups in the achieved BP levels could have conditioned the slightly higher risk of MI in the ARB group. ${ }^{22}$

\section{COMPARATIVE ASSESSMENT}

Although the age of patients was comparable in the JIKEI and Kyoto studies, BP at entry was substantially higher in the latter study (157/88 vs. $139 / 81 \mathrm{~mm} \mathrm{Hg}$ ). Notwithstanding, achieved BP was almost identical in the two studies, thereby suggesting a more marked antihypertensive response in the setting of the Kyoto Study. The lack of differences in the achieved BP between the valsartan group and the control group was a constant of the two studies. It suggests that valsartan might exert protective effects on the cardiovascular system beyond those expected on the basis of $\mathrm{BP}$ reduction. We made a pooled analysis of Jikei and Kyoto studies (Figure 1). Overall, valsartan significantly reduced the risk of the primary composite outcome (by $42 \% ; P<0.0001$ ), angina pectoris (by $38 \% ; P<0.0001$ ), heart failure requiring hospitalization (by $43 \% ; P=0.013$ ) and cerebrovascular events (by $42 \% ; P=0.002$ ). The protective effect on the dissecting aneurysm of aorta bordered statistical significance. It is noteworthy that a remarkable consistency of effects on each of the various end points was observed in both studies (Figure 1).

At variance with the Jikei and Kyoto studies, two other studies conducted with another ARB, candesartan, in Asian people, failed to show outcome benefits in the ARB group. ${ }^{23,24}$ The first of these studies, the Candesartan Antihypertensive Survival Evaluation in Japan (CASE-J), was a comparison between candesartan and amlodipine in hypertensive patients. ${ }^{23}$ The second study, the Heart Institute of Japan Candesartan Randomized Trial for Evaluation in Coronary Artery Disease (HIJ-CREATE), was a comparison between candesartan and a non-ARB-based regimen in patients with coronary artery 


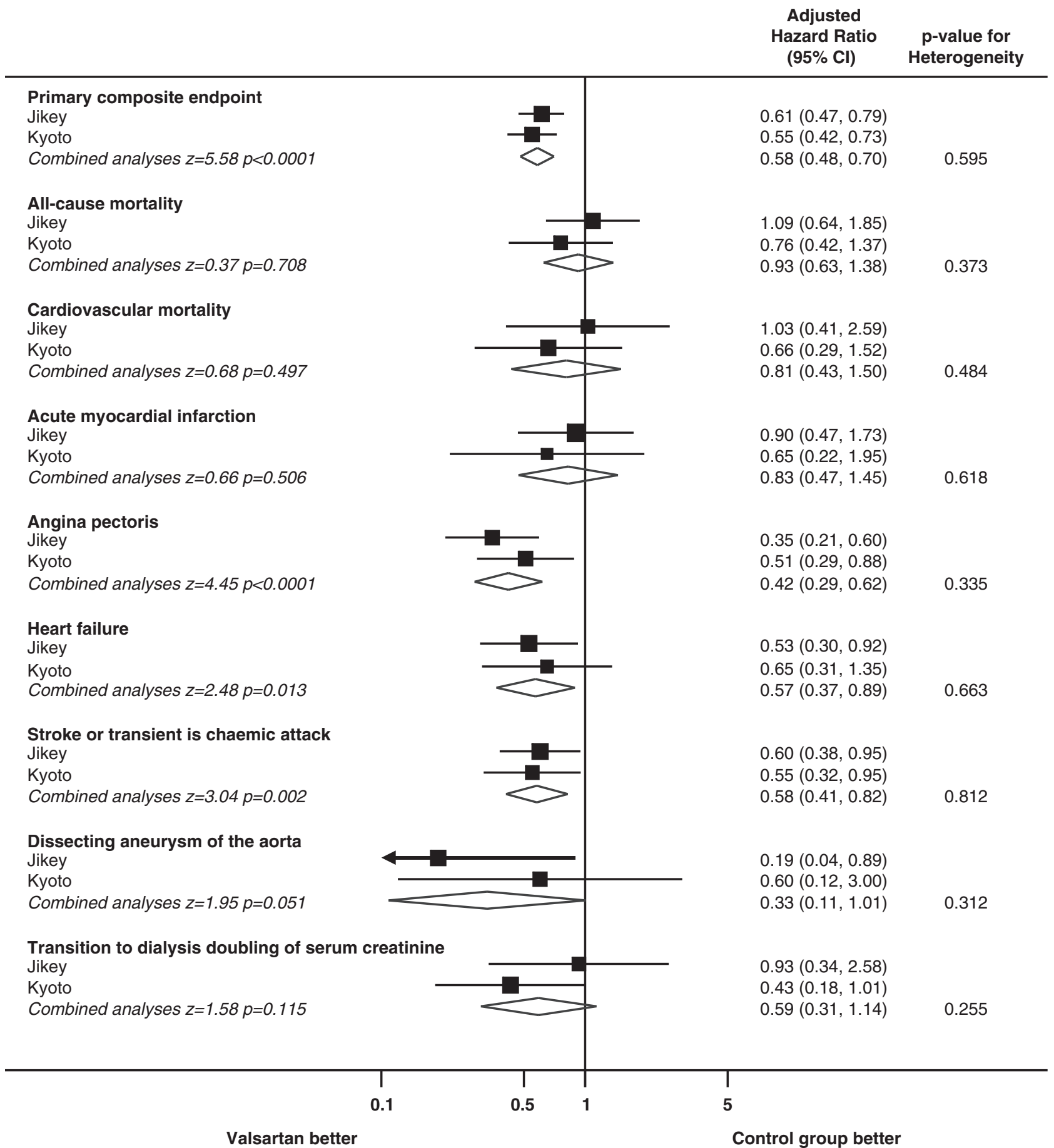

Figure 1 Pooled analysis of the Jikei and Kyoto studies. Valsartan significantly reduced the risk of the primary composite outcome (by $42 \% ; P<0.0001$ ), angina pectoris (by 38\%; $P<0.0001$ ), heart failure requiring hospitalization (by $43 \% ; P=0.013$ ) and cerebrovascular events (by $42 \% ; P=0.002$ ).

disease and hypertension. ${ }^{24}$ In both studies, the primary composite end point and its components did not show any statistical differences between the groups. ${ }^{23,24}$ As commented by Messerli, it is difficult to ascertain whether the differences with respect to the two valsartan studies may be attributable to the specific ARB molecule, the trial design, the clinical characteristics of the patient population or the concomitant medications. ${ }^{21}$ Similar to the CASE-J and HIJ-CREATE studies, the JIKEI and Kyoto studies used a prospective randomized open blinded end point (PROBE) design and a wide composite end point, which included relatively soft outcome events such as angina pectoris and TIA. A common criticism shared by studies conducted with PROBE design is the observation that soft end points are likely to be affected by the judge of the doctor-in-charge, which could be conditioned by the awareness of randomization arm. It could be argued that harder component of the composite end point such as stroke alone ${ }^{9}$ and combined with TIA, ${ }^{8}$ as well as heart failure, ${ }^{8}$ were significantly less frequent in the valsartan group than in the control group. 
A randomized double-blind design remains the standard for drug evaluation. In the VALUE trial, a double-blind comparison between valsartan and amlodipine in hypertensive patients at high cardiovascular risk, a wide composite end point of cardiovascular morbidity and mortality did not differ between the two groups, with MI occurring less frequently with amlodipine $(P=0.02) .{ }^{22}$ However, the differences between the two groups in the risk of MI were largely confined to the first 3 months of the study, in which achieved systolic BP was about $4.0 \mathrm{~mm} \mathrm{Hg}$ lower in the amlodipine group. The BP gradient between the two groups tended to vanish over the subsequent follow-up period and also the risk of MI did no longer differ significantly between the groups. ${ }^{22}$

\section{CONCLUSION}

ARBs are effective and very well tolerated drugs, which should be considered as first-line antihypertensive agents. ${ }^{1}$ Therapeutic interventions with $A R B s$ are effective to slow down or block the progression of cardiovascular disease at different steps of the 'cardiovascular disease continuum, ${ }^{25}$ with measurable clinical benefits. As each ARB is characterized by specific properties that may influence its clinical efficacy and differences among available ARBs emerged from clinical studies, generalization of results obtained with a specific ARB to all available ARBs may not be justified. The Jikei $^{8}$ and Kyoto ${ }^{9}$ studies provided independent and concordant evidence indicating that valsartan, on top of optimized pharmacological therapy, reduces the risk of CV events and, in particular, the risk of stroke in Asian patients with hypertension and high cardiovascular risk. In patients with heart failure and left ventricular dysfunction, valsartan on top of optimized therapy including an ACE inhibitor, significantly reduced the morbidity/mortality combined end point and reduced the rate of rehospitalization due to worsening of heart failure. ${ }^{26}$ In patients with MI complicated by heart failure or left ventricular dysfunction, alone or combined, valsartan reduced morbidity and mortality, with a protective effect similar to the ACE-inhibitor comparator captopril. ${ }^{27}$ These findings support valsartan as an ARB with strong scientific documentation along the different steps of the cardiovascular disease continuum.

\section{CONFLICT OF INTEREST}

The authors declare no conflict of interest.

1 Mancia G, De Backer G, Dominiczak A, Cifkova R, Fagard R, Germano G, Grassi G, Heagerty AM, Kjeldsen SE, Laurent S, Narkiewicz K, Ruilope L, Rynkiewicz A, Schmieder RE, Boudier HA, Zanchetti A, Vahanian A, Camm J, De Caterina R, Dean V, Dickstein K, Filippatos G, Funck-Brentano C, Hellemans I, Kristensen SD, McGregor K, Sechtem U, Silber S, Tendera M, Widimsky P, Zamorano JL, Erdine S, Kiowski W, Agabiti-Rosei E, Ambrosioni E, Lindholm LH, Viigimaa M, Adamopoulos S, Bertomeu V, Clement D, Farsang C, Gaita D, Lip G, Mallion JM, Manolis AJ, Nilsson PM, O'Brien E, Ponikowski P, Redon J, Ruschitzka F, Tamargo J, van Zwieten P, Waeber B, Williams B. 2007 Guidelines for the management of arterial hypertension: the task force for the management of arterial hypertension of the European Society of Hypertension (ESH) and of the European Society of Cardiology (ESC). J Hypertens 2007; 25: 1105-1187.

2 Masoudi FA, Rathore SS, Wang Y, Havranek EP, Curtis JP, Foody JM, Krumholz HM. National patterns of use and effectiveness of angiotensin-converting enzyme inhibitors in older patients with heart failure and left ventricular systolic dysfunction. Circulation 2004; 110: 724-731.

3 Turnbull F. Effects of different blood-pressure-lowering regimens on major cardiovascular events: results of prospectively-designed overviews of randomised trials. Lancet 2003; 362: 1527-1535.

4 Staessen JA, Wang JG, Thijs L. Cardiovascular protection and blood pressure reduction: a meta-analysis. Lancet 2001; 358: 1305-1315.
5 Law MR, Morris JK, Wald NJ. Use of blood pressure lowering drugs in the prevention of cardiovascular disease: meta-analysis of 147 randomised trials in the context of expectations from prospective epidemiological studies. BMJ 2009; 338: b1665.

6 Verdecchia P, Reboldi G, Angeli F, Gattobigio R, Bentivoglio M, Thijs L, Staessen JA, Porcellati $C$. Angiotensin-converting enzyme inhibitors and calcium channel blockers for coronary heart disease and stroke prevention. Hypertension 2005; 46: 386-392.

7 Verdecchia P, Angeli F, Cavallini C, Gattobigio R, Gentile G, Staessen JA, Reboldi G. Blood pressure reduction and renin-angiotensin system inhibition for prevention of congestive heart failure: a meta-analysis. Eur Heart J 2009; 30: 679-688.

8 Mochizuki S, Dahlof B, Shimizu M, Ikewaki K, Yoshikawa M, Taniguchi I, Ohta M, Yamada T, Ogawa K, Kanae K, Kawai M, Seki S, Okazaki F, Taniguchi M, Yoshida S, Tajima N. Valsartan in a Japanese population with hypertension and other cardiovascular disease (Jikei Heart Study): a randomised, open-label, blinded endpoint morbidity-mortality study. Lancet 2007; 369: 1431-1439.

9 Sawada T, Yamada H, Dahlof B, Matsubara H. Effects of valsartan on morbidity and mortality in uncontrolled hypertensive patients with high cardiovascular risks: KYOTO HEART Study, Eur Heart J 2009; 30: 2461-2469.

10 Kubo M, Kiyohara Y, Kato I, Tanizaki Y, Arima H, Tanaka K, Nakamura H, Okubo K, lida $M$. Trends in the incidence, mortality, and survival rate of cardiovascular disease in a Japanese community: the Hisayama study. Stroke 2003; 34: 2349-2354.

11 Dahlof B, Devereux RB, Kjeldsen SE, Julius S, Beevers G, de Faire U, Fyhrquist F, Ibsen H, Kristiansson K, Lederballe-Pedersen O, Lindholm LH, Nieminen MS, Omvik P, Oparil S, Wedel H. Cardiovascular morbidity and mortality in the Losartan Intervention For Endpoint Reduction in hypertension Study (LIFE): a randomised trial against atenolol. Lancet 2002; 359: 995-1003.

12 Reboldi G, Angeli F, Cavallini C, Gentile G, Mancia G, Verdecchia P. Comparison between angiotensin-converting enzyme inhibitors and angiotensin receptor blockers on the risk of myocardial infarction, stroke and death: a meta-analysis. J Hypertens 2008; 26: $1282-1289$

13 Yusuf S, Diener HC, Sacco RL, Cotton D, Ounpuu S, Lawton WA, Palesch Y, Martin RH, Albers GW, Bath P, Bornstein N, Chan BP, Chen ST, Cunha L, Dahlof B, De Keyser J, Donnan GA, Estol C, Gorelick P, Gu V, Hermansson K, Hilbrich L, Kaste M, Lu C, Machnig T, Pais P, Roberts R, Skvortsova V, Teal P, Toni D, VanderMaelen C, Voigt T, Weber M, Yoon BW. Telmisartan to prevent recurrent stroke and cardiovascular events. N Engl J Med 2008; 359: 1225-1237.

14 Li J, Culman J, Hortnagl H, Zhao Y, Gerova N, Timm M, Blume A, Zimmermann M, Seidel K, Dirnagl U, Unger T. Angiotensin AT2 receptor protects against cerebral ischemia-induced neuronal injury. FASEB J 2005; 19: 617-619.

15 Krikov M, Thone-Reineke C, Muller S, Villringer A, Unger T. Candesartan but not ramipril pretreatment improves outcome after stroke and stimulates neurotrophin BNDF/TrkB system in rats. J Hypertens 2008; 26: 544-552.

16 Dai WJ, Funk A, Herdegen T, Unger T, Culman J. Blockade of central angiotensin AT(1) receptors improves neurological outcome and reduces expression of AP-1 transcription factors after focal brain ischemia in rats. Stroke 1999; 30: 2391-2398; discussion 2398-9.

17 Verma S, Strauss M. Angiotensin receptor blockers and myocardial infarction. BMJ 2004; 329: 1248-1249.

18 Volpe M, Mancia G, Trimarco B. Angiotensin II receptor blockers and myocardial infarction: deeds and misdeeds. J Hypertens 2005; 23: 2113-2118.

19 Verdecchia P, Angeli F, Gattobigio R, Reboldi GP. Do angiotensin II receptor blockers increase the risk of myocardial infarction? Eur Heart J 2005; 26: 2381-2386.

20 Yusuf S, Teo K, Anderson C, Pogue J, Dyal L, Copland I, Schumacher H, Dagenais G, Sleight P. Effects of the angiotensin-receptor blocker telmisartan on cardiovascular events in high-risk patients intolerant to angiotensin-converting enzyme inhibitors: a randomised controlled trial. Lancet 2008; 372: 1174-1183.

21 Messerli FH, Bangalore S, Ruschitzka F. Angiotensin receptor blockers: baseline therapy in hypertension? Eur Heart J 2009; 30: 2427-2430.

22 Julius S, Kjeldsen SE, Weber M, Brunner HR, Ekman S, Hansson L, Hua T, Laragh J, Mclnnes GT, Mitchell L, Plat F, Schork A, Smith B, Zanchetti A. Outcomes in hypertensive patients at high cardiovascular risk treated with regimens based on valsartan or amlodipine: the VALUE randomised trial. Lancet 2004; 363: 2022-2031.

23 Ogihara T, Nakao K, Fukui T, Fukiyama K, Ueshima K, Oba K, Sato T, Saruta T. Effects of candesartan compared with amlodipine in hypertensive patients with high cardiovascular risks: candesartan antihypertensive survival evaluation in Japan trial. Hypertension 2008; 51: 393-398.

24 Kasanuki $\mathrm{H}$, Hagiwara N, Hosoda S, Sumiyoshi T, Honda T, Haze K, Nagashima M, Yamaguchi J, Origasa H, Urashima M, Ogawa H. Angiotensin II receptor blocker-based vs non-angiotensin II receptor blocker-based therapy in patients with angiographically documented coronary artery disease and hypertension: the Heart Institute of Japan Candesartan Randomized Trial for Evaluation in Coronary Artery Disease (HIJ-CREATE). Eur Heart J 2009; 30: 1203-1212.

25 Dzau V, Braunwald E. Resolved and unresolved issues in the prevention and treatment of coronary artery disease: a workshop consensus statement. Am Heart J 1991; 121: $1244-1263$.

26 Cohn JN, Tognoni G. A randomized trial of the angiotensin-receptor blocker valsartan in chronic heart failure. N Engl J Med 2001; 345: 1667-1675.

27 Pfeffer MA, McMurray JJ, Velazquez EJ, Rouleau JL, Kober L, Maggioni AP, Solomon SD, Swedberg K, Van de Werf F, White H, Leimberger JD, Henis M, Edwards S, Zelenkofske S, Sellers MA, Califf RM. Valsartan, captopril, or both in myocardial infarction complicated by heart failure, left ventricular dysfunction, or both. $\mathrm{N} \mathrm{Engl} \mathrm{J}$ Med 2003; 349: 1893-1906. 